\title{
Deficiency in Investment in Early Education: The Second-Best Optimal Levels of Investment in Later Education and Human Capital
}

\author{
Phung Xuan Nha ${ }^{1} \&$ Pham Xuan Hoan ${ }^{1}$ \\ ${ }^{1}$ Vietnam National University, Hanoi, Vietnam \\ Correspondence: Phung Xuan Nha, Vietnam National University, Hanoi, Vietnam. E-mail: nhapx@vnu.edu.vn
}

Received: May 8, 2014 Accepted: July 9, 2014 Online Published: August 15, 2014

doi:10.5539/ass.v10n18p96 URL: http://dx.doi.org/10.5539/ass.v10n18p96

\begin{abstract}
This paper extends the work of Cunha et al. (2005) by replacing an exogenously-determined target level of human capital with the optimization of a net benefit function, to address the issue of the optimal levels of education and human capital when there is an investment-deficiency in early ages. The study shows that it is not socially optimal to completely offset an investment-deficiency in early ages. Indeed, in the case of direct complementarity, an early investment-deficiency should be optimally followed by an even greater investment-deficiency the later stage. The paper rings a bell on the ambitious plan on tertiary education development in Vietnam. (Classification: J3, E2, I00.)
\end{abstract}

Keywords: education investment deficiency, human capital, ooptimal investment, remediation

\section{Introduction}

Human capital is an important factor of production and it has been included in the production function of various well-known publications such as Schultz (1961), Mankiw et al. (1992), Bils and Klenow (2000), Jones (2002) etc.

Human capital represents all the resources which people utilize to augment their personal productivity. Conceptually, human capital may be created by investing in health, education and training, information, among many others. Traditionally, economists have focused on education as the principal source of human capital. This approach can be found in Imhoff (1988), Mankiw et al. (1992), Bils and Klenow (2000), Ozcan et al. (2000), among many other papers.

Education is a special activity. To some extent, education can be seen as people's "right", because thanks to education they can read and write, thus they can enjoy more their lives. But, definitely, education improves human capital, which in turn, improves productivity, so education can be seen as an investment. An increase in investment would lead to an increase in the level of human capital, which in turns, leads to a higher level of productivity. Thus, theoretically, there must be an optimal level of investment into education so as to maximize the benefit of human being.

Empirical researchers have calculated the rates of return to primary education, secondary education and tertiary education for many countries since the 1950s. Psacharopoulos and Patrinos (2002, Table 1) list the rates for over 80 countries. It appears from this list that the rates of return are highest with primary education, followed by second education and finally by tertiary education. In details, while on average, the rate of return to primary education is about $20 \%$, the rates for secondary education and tertiary education are only $13 \%$ and $10 \%$ respectively in these countries. Based on this fact, Psacharopoulos and Patrinos (2002) infer that the current level of investment in primary education and secondary in most countries and regions in the world is low relative to its optimal level.

Now, we define primary and secondary education as "early education" while tertiary education as "late education" and address the issue: how should countries change the investment in late education in case the investment in early education is below its optimal level, so as to maximize the net benefit of investment into education as a whole (including both early and late education)? In other words, what is the optimal level of investment in later education, conditional on the investment-deficiency in early ages?

Cunha et al. (2005) assume an exogenous level of human capital of a cohort $H$, which is determined by investments into early education $I_{1}$ and later education $I_{2}$, and analyse aspects of using investment into late 
education $I_{2}$ to remediate deficiency in investment into early education $I_{1}$.

Table 1. Complementarity and substitution between investments in education in different years

\begin{tabular}{ll}
\hline Range of $\phi+v$ & \\
\hline$\phi+v<1$ & Direct complementarity \\
$\phi+v=1$ & Independence \\
$\phi+v>1$ & Direct substitutes \\
& (If $v=1:$ Perfect substitutes) \\
\hline
\end{tabular}

Source: Authors' definition

This paper extends the work of Cunha et al. (2005) by replacing their exogenously-determined target level of human capital with the optimization of a conventional social welfare function. Thus, the paper can give insights into the optimal level of human capital, which is ignored in the Cunha et al. (2005). The conclusions on using investment in late education to remediate low investment in early education also become more practical, because the final target of investments in education is not to reach a certain level of human capital, as being assumed in Cunha et al. (2005), but to maximize people's welfare. The other aspect of this paper is to set some lights on the ambitious master plan on tertiary education development in Vietnam, based on the implication of the model to be developed in this paper.

The paper is structured as follows: Part 1 is the introduction, expressing the issues to be addressed; Part 2 provides a list of concepts to be used in the paper; Part 3 sets up the model; Part 4 solves the model and analyses different kinds of appropriate remediation; Part 5 analyses the real situation of investment in education in Vietnam and rings a bell on her ambitious master plan on higher education development; and Part 6 is the conclusion.

\section{Concepts}

For the purpose of this paper, the following concepts, which are presented in Hoan Pham Xuan (2009) and discussed in more details in Cunha et al. (2005) (Note 1), relating to the production of human capital from investments into education will be used: The investments in education in two periods (Note 2) are direct complements or independent or direct substitutes if, other things being equal, a higher level of investment in education in one period will result in a higher productivity, no change in productivity or lower productivity of the investment in education in the other period, in production of human capital. In special case of perfect substitutes, one unit of investment in education in one period can perfectly substitute for another unit of investment in education in another period.

Also, the following concepts relating to optimal level of human capital and remediation of human capital will be used:

1) The first-best optimal level of human capital: This is the outcome when there are no exogenous constraints on investment in education in any period, so investment in each period of education is determined optimally.

2) The second-best optimal level of human capital: This is the outcome when the investment in early education (Note 3) is exogenously set either below or above its optimal level given by the first-best. The investment in later education is optimally set conditional on the constrained level of investment in early education. This paper focuses on the case when the investment in early education is exogenously set below its optimal level given by the first-best.

3) Full remediation of human capital is the case when the deficiency in investment in early education is fully offset by an increase in investment in later education such that there is no deficiency in human capital, which is the second-best optimal human capital, is equal to its first-best optimal level. Investment in later education is greater than its first-best optimal level.

4) Partial remediation of human capital is the case when the deficiency in investment in early education is partially offset by an increase in investment in later education above its first-best level, such that the second-best optimal human capital is below its first-best optimal level. Investment in later education is greater than its first-best optimal level. 
5) No remediation of human capital is the case when the deficiency in investment in early education is not offset by an increase in investment in later education above its first-best level. Investment in later education is at its first-best optimal level. The human capital deficiency is greater than for the case of partial remediation.

6) Negative remediation of human capital is the case when the deficiency in investment in early education is accompanied by a decrease in investment in later education to below its first-best level. The human capital deficiency is greater than for the case of no remediation.

\section{Setting up the Model}

\subsection{The Model in General Case}

First, assume that a typical cohort of an economy is born in period 1 . After birth, every person spend period 1 to period $m$ for education; with $m$ being any integer like 1,2,3...; and with the direct investment being made for the cohort's education being $I_{1}, I_{2}, \ldots$ and $I_{m}$ respectively. Direct investment refers to any visible costs, such as the cost of teachers, other operational costs of schools, textbools and stationary etc., but not refer to invisible costs such as the indirect cost of study time. Having finished these $m$ periods of education, the cohort acquired a human capital stock $H$, which is positively related to the direct investment during these $m$ education periods as presented in Hoan Pham Xuan (2009) as:

$$
H=l^{\phi}\left(I_{1}^{v}+I_{2}^{v}+\ldots+I_{m}^{v}\right)^{(1-\phi) / v}
$$

where $1 \geq v>0$ and $1>\phi>0$ and $l>0$ is the size of the cohort.

For simplicity and without loss of insight, this paper assumes that there is no on-the-job training so human capital stock of the cohort given by (1) is constant during its working periods. Human capital is embodied in the individual, so once the cohort retires and leave the workforce, this human capital stock will fully depreciate. Note again that, no on-the-job training may not realistic in the real world, but this assumption does not affect the insight and the conclusions made from our model at all.

Before going further with the model setting, we look at a simple case of $m=2$ to clarify the role of technology in production of human capital as given in (1). With a normalization of the cohort size to be one unit, function (1) becomes:

$$
H=\left(I_{1}^{v}+I_{2}^{v}\right)^{(1-\phi) / v}
$$

The total derivative of human capital stock with respect to the investments in two periods from (2) is:

$$
\partial^{2} H / \partial I_{1} \partial I_{2}=(1-\phi-v)(1-\phi)\left(I_{1}^{v}+I_{2}^{v}\right)^{(1-\phi-2 v) / v} / I_{1}^{1-v} I_{2}^{1-v}
$$

Because $1 \geq v>0,1>\phi>0$ and the investment $I_{1}, I_{2}>0$ equation (3) says that:

1) If $\phi+v<1$, then $\partial^{2} H / \partial I_{1} \partial I_{2}>0$, then the investments in education in two periods are direct complements.

2) If $\phi+v=1$, then $\partial^{2} H / \partial I_{1} \partial I_{2}=0$, then the investments in education in two periods are independent.

3) If $\phi+v>1$, then $\partial^{2} H / \partial I_{1} \partial I_{2}<0$, then the investments in education in two periods are direct substitutes. In special case of $v=1$, its maximum possible value (2) becomes $H=\left(I_{1}+I_{2}\right)^{(1-\phi)}$, then the investment in education in two periods are perfect substitutes.

Second, assume that having finished education, the cohort works from period $m+1$ to the retirement period $p$, (for example, if one period is seen as one year, then in Vietnam $p=60$ ). In these working periods, the cohort uses the stream of (non-human) capital stock of $K_{m+1}, K_{m+2}, \ldots$ and $K_{p}$ to produce the stream of output $Y_{m+1}$, $Y_{m+2}, \ldots$ and $Y_{p}$ correspondingly.

Third, assume that, output $Y_{j}$ in any period $j$ follows a constant returns to scale Cobb-Douglas production function of physical capital stock $K_{j}$ and human capital stock $H_{j}$, with $j \in(m+1, p)$, as: 


$$
Y_{j}=K_{j}^{\alpha} H_{j}^{1-\alpha}
$$

where $1>\alpha>0$.

The model (in this general case) becomes: Maximizing the living standard of the cohort, which is defined as the total output after being net of the physical capital cost of production and direct cost of education of the cohort; that is maximizing:

$$
T=\left(Y_{m+1}+Y_{m+2}+\ldots+Y_{n}\right)-\sigma\left(K_{m+1}+K_{m+2}+\ldots+K_{n}\right)-\left(I_{1}+I_{2}+\ldots+I_{m}\right)
$$

subject to the human capital acquisition function (1) and the production function (4), by choosing the stream of optimal direct investment in education $I_{1}, I_{2}, \ldots, I_{m}$ and the stream of optimal physical capital stock $K_{m+1}$, $K_{m+2}, \ldots, K_{p}$.

Note that, for simplicity and without loss of insight, in deriving the maximization problem (5) this paper assumes that the cohort borrows all its needs of physical capital for production from a competitive market at a constant rental rate of $\sigma$. In a compatitive market, $\sigma$ is equal to the sum of depreciation rate and interest rate.

The indirect cost of study time is captured in the net benefit function (5) because any increase in the periods of education $m$ will, given the exogenous retirement period $p$, be offset by exactly the same reduction in the number of periods of work.

\subsection{The Simplified Model}

Without loss of insight and for the simplicity of model solving, similar to Hoan Pham Xuan (2009) and Cunha et al. (2005), we focus on the case with only 2 periods of education as presented in equation (2). Period 1 education, then, can be interpreted as a representation of early years of education such as pre-school, primary and secondary education, whereas periods 2 educations can be interpreted as a representation of later years of education such as tertiary education.

Our research aims to answer what would be the second-best optimal levels of human capital and investment in later education if the investment in early education is exogenously made below its first- best optimal level. Therefore, we need to make an extra assumption that the investment in early education is exogenously made at $I_{1}=\bar{I}_{1}<I_{1}^{1 s t}$ best . With this extra assumption, the human capital function in (2) becomes:

$$
H=\left(\bar{I}_{1}^{v}+I_{2}^{v}\right)^{(1-\phi) / v}
$$

And model will be simplified to: Maximizing the cohort's living standard function:

$$
T=\left(Y_{m+1}+Y_{m+1}+\ldots+Y_{p}\right)-\sigma\left(K_{m+1}+K_{m+2}\right)-\left(\bar{I}_{1}+I_{2}\right)
$$

subject to human capital production function (6) and output production function (4), by choosing the (second-best) optimal level of investment in late education $I_{2}$.

\section{Solving the Model}

The production function in (4) and the first order condition with respect to physical capital $K_{j}$ with $j=m+1, m+2, \ldots, p$ from (7) for physical capital stock $K_{j}$ together imply that:

$$
K_{j}=\alpha^{1 / 1-\alpha} \sigma^{1 / \alpha-1} H_{j}
$$

Recall that, without loss of insights, we have assumed no capital depreciation nor on-the-job training so human capital stock is constant during working life. Thus, the human capital stock of the cohort $H_{j}$ is constant during the working periods. Equation (8), then, says that acting optimally the cohort should use a constant physical capital stock $K_{j}$ for production in her working life. Economically, this ( $K_{j}$ is constant) is possible because of our earlier assumption that the cohort is small and lives in an open world, so it can borrow whatever the level of physical capital it may need to optimize its production. Equation (4), in turns, implies that the cohort produces a constant level of output $Y_{j}$ every period. For simplicity of notation, from now on the time subscript $j$ of these variables will be dropped.

It can be seen from (6) that $H$ is a function of investments in education $\left(\bar{I}_{1}\right.$ and $\left.I_{2}\right)$. Equation (8), in turns, implies that $K$ can be transformed to be a function of $\bar{I}_{1}$ and $I_{2}$. Equation (4), in turns, implies that $Y$ can be transformed to be a function of $\bar{I}_{1}$ and $I_{2}$. Equation (7), finally, implies that $T$ can be transformed to be a 
function $\bar{I}_{1}$ and $I_{2}$. More specifically, applying this change of substitutions, our maximization in (7) becomes maximizing:

$$
T=(p-2) \sigma^{\alpha / 1-\alpha} l_{\phi}\left(\alpha^{\alpha / 1-\alpha}-\alpha^{1 / 1-\alpha}\right)\left(\bar{I}_{1}^{v}+I_{2}^{v}\right)^{(1-\phi) / v}-\left(\bar{I}_{1}+I_{2}\right)
$$

by choosing the (second-best) optimal level of investment in period 2 education $I_{2}$.

The first order condition for investment in period 2 education $I_{2}$ from (9) gives the following result:

$$
\left(\bar{I}_{1}^{v}+I_{2}^{v}\right)^{(\phi+v-1) / v} I_{2}^{1-v}=Z
$$

Where

$$
Z=(1-\phi)(p-2) \sigma^{\alpha / \alpha-1} l^{\phi}\left(\alpha^{\alpha / 1-\alpha}-\alpha^{1 / 1-\alpha}\right)
$$

Note that, $Z$ looks complicated, but actually the message of this result is very simple that it is a constant, because it is totally determined by exogenous parameters. From now on, for simplicity, we just need to note that $Z$ is a constant and do not have to care that "it looks complicated"

Before going further, it's helpful to summarize at this moment that given the exogenous level of investment in period 1 education $\bar{I}_{1}$, the second-best optimal level of direct investment in period 2 education will be implicitly given by (10). Then, the second-best optimal level of human capital stock will be implicitly given by (6). Thus, basically equation (10) and (6) will be used for our research in the remaining part of this paper.

Applying the implicit rule of differentiation, the first derivative of the second-best optimal level of investment in period 2 education $\left(I_{2}^{2 n d ~ b e s t}\right)$ with respect to the exogenous investment in period 1 education $\left(\bar{I}_{1}\right)$ from $(10)$, after re-arrangement is:

$$
\partial I_{2}^{2 n d b e s t} / \partial \bar{I}_{1}=-(\phi+v-1) \bar{I}_{1}^{v-1} I_{2}^{1-v} /(\phi+v-1)+(1-v) \bar{I}_{1}^{v} I_{2}^{-v}\left(\bar{I}_{1}^{v}+I_{2}^{v}\right)
$$

From (12), the impact of low (in comparison with the first-best optimal level) investment in period 1 education on the second-best level of investment in period 2 education and thereby on the degree of remediation of human capital can be deduced. We examine the impact under various cases:

Case 1: If investments in periods 1 and 2 education are direct complements, which is represented by $(\phi+v)<1$

then, as shown in Appendix 2, ${ }^{2 I_{2}^{2 n d b e s t}} / \partial \bar{I}_{1}>0$ around the first-best. This implies that, relative to first-best level, a lower than first-best optimal level of investment in period 1 education should be followed by a lower than

\begin{tabular}{|c|c|c|c|c|}
\hline & Case 1 & Case 2 & Case 3 & Case 4 \\
\hline Characteristic & $\begin{array}{l}\text { Direct } \\
\text { Complementarity } \\
\phi+v<1\end{array}$ & $\begin{array}{l}\text { Independence } \\
\phi+v=1\end{array}$ & $\begin{array}{l}\text { Substitution } \\
\text { (but not perfect) } \\
\phi+v>1, v \neq 1 \text { ) }\end{array}$ & $\begin{array}{l}\text { Perfect } \\
\text { Substitution } \\
v=1\end{array}$ \\
\hline $\begin{array}{l}I_{2}^{\text {2nd best }} \\
H^{2 n d ~ b e s t}\end{array}$ & $\begin{array}{l}I_{2}^{2 n d ~ b e s t}<I_{2}^{1 s t \text { best }} \\
H^{\text {2nd best }}<H^{1 \text { st best }}\end{array}$ & $\begin{array}{l}I_{2}^{2 n d ~ b e s t}=I_{2}^{1 \text { st best }} \\
H^{2 \text { nd best }}<H^{1 s t ~ b e s t}\end{array}$ & $\begin{array}{l}I_{2}^{2 \text { 2nd best }}>I_{2}^{\text {Ist best }} \\
H^{2 \text { nd best }}>H^{1 \text { st best }}\end{array}$ & $\begin{array}{l}I_{2}^{\text {Lnd best }}>I_{2}^{1 S l \text { best }} \\
H^{2 n d \text { best }}=H^{1 s t \text { best }}\end{array}$ \\
\hline $\begin{array}{l}\text { Conclusion } \\
H^{2 n d ~ b e s t}\end{array}$ & Negative remediation & $\begin{array}{r}\text { No remediation } \\
\text { Lowe }\end{array}$ & $\begin{array}{l}\text { Partial remediation } \\
\text { Highest }\end{array}$ & Full remediation \\
\hline
\end{tabular}
first-best optimal level of investment in period 2 education. This also implies that there is negative remediation of human capital at the second-best outcome. The result is illustrated in Figure 1 and in column 2 of Table 2.

Table 2. Appropriate remediation under difference scenario

Source: Authors' research results 


\begin{tabular}{|c|c|c|}
\hline $\bar{I}_{1}<I_{1}^{1 s t ~ b e s t}$ & $I_{1}^{1 s t ~ b e s t}$ & $I_{1}$ \\
\hline$I_{2}^{2 n d ~ b e s t}<I_{2}^{1 s t ~ b e s t}$ & $I_{2}^{1 s t ~ b e s t}$ & $I_{2}$ \\
\hline$H^{2 n d}$ best $<H^{1 s t ~ b e s t}$ & $H^{1 s t ~ b e s t}$ & $H$ \\
\hline
\end{tabular}

Figure 1. The case of direct complementarity: Negative remediation

Case 2: If investments in periods 1 and 2 education are independent, which is represented by $(\phi+v)=1$, then the second-best level of investment in period 2 education is independent of the exogenous investment in period 1 education. This also means that the second-best level of education investment in period 2 is equal to its first-best level. That is no remediation is the second-best optimal. The result is illustrated in Figure 2 and in column 3 of Table 2.

\begin{tabular}{ccc}
$\bar{I}_{1}<I_{1}^{1 \text { st best }}$ & $I_{1}$ \\
\hline & $I_{2}^{\text {2nd best }}=I_{2}^{\text {1st best }}$ & $I_{2}$ \\
\hline$H^{\text {2nd dest }}<H^{\text {1st best }}$ & $H$ \\
\hline
\end{tabular}

Figure 2. The case of independence: No remediation

Case 3: If investments in periods 1 and 2 education are direct substitutes, (but not perfect substitutes) which is represented by $(\phi+v)>1$, (and $v \neq 1$ ), then as shown in Appendix 2, $\partial I_{2}^{2 \text { ndbest }} / \partial \bar{I}_{1}<0$ around the first-best. Thus, a lower than first-best level of investment in period 1 education should be followed by a higher than first-best level of investment in period 2 education. Thus, there is some remediation of human capital. Naturally, we want to know if such remediation is full or only partial. To answer this question, we take differentiation of (6) with respect to the exogenous level of investment in period 1 education $\bar{I}_{1}$ and derive the following derivative:

$$
\left.\partial H^{2 n d b e s t} / \partial \bar{I}_{1}=(1-\phi)\right)^{\phi}\left(\bar{I}_{1}^{v}+I_{2}^{v}\right)^{\frac{(1-\phi)}{v}-1} *(1-v) \bar{I}_{1}^{2 v-1} I_{2}^{-v}\left(\bar{I}_{1}^{v}+I_{2}^{v}\right) /(\phi+v-1)+(1-v) \bar{I}_{1}^{v} I_{2}^{-v}\left(\bar{I}_{1}^{v}+I_{2}^{v}\right)
$$

Because $(\phi+v)>1$ and all the parameters are all in the $(0,1)$ range, it is implied from (13) that $\partial H^{2 n d b e s t} / \partial \bar{I}_{1}>0$, thus the second-best optimal level of human capital is reduced by below optimal investment in period 1 education. That is a partial remediation is the second best optimal. The result is illustrated in Figure 3 and in column 4 of Table 2.

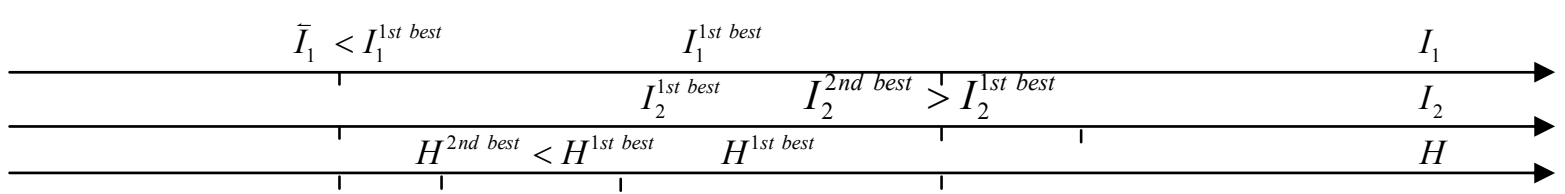

Figure 3. The case of direct substitution (not perfect): Partial remediation

Case 4: If investments in periods 1 and 2 are perfect substitutes, which is represented by $1=v$, equation (13) shrinks to $\partial H^{2 n d b e s t} / \partial \bar{I}_{1}=0$, saying that the second-best optimal level of human capital is equal to its first-best optimal level. That is, the increased investment in period 2 education is sufficiently great to cause full remediation of human capital. The result is illustrated in Figure 4 and in column 5 of Table 2. 


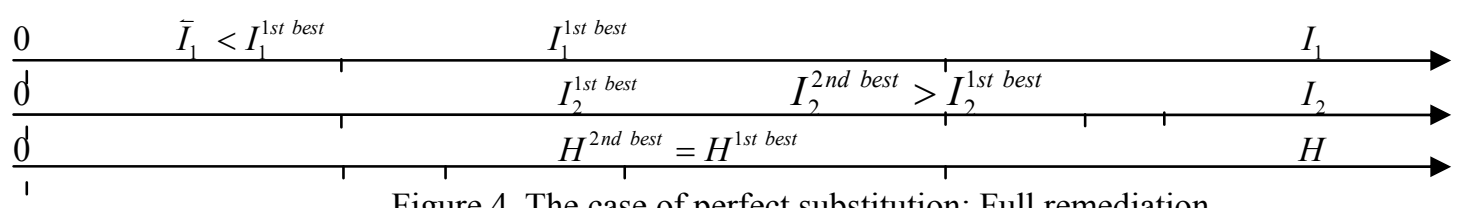

Figure 4. The case of perfect substitution: Full remediation

\section{Evidence of Direct Complementarity and Implication for Vietnam}

\subsection{Evidence of Direct Complementarity}

Cunha et al. (2005) reviews three intervention programs that targeted preschool and primary students; and eight intervention programs that targeted secondary and college students in the United States to determine if early intervention or late intervention is more effective.

Commonly the intervention period is around 3-5 years, but for some programs the interventions last for up to eight years. Interventions for primary students may include services such as subsidized health service and meals, extra classroom sessions, individually-tailored curriculum for each child, home visits by social workers to involve the mother in the child's educational process, reduced student-teacher ratio, fieldtrips and some summer activities. The intervention to secondary and college students included services such as long-term mentoring, substantial academic support, help with college application and financial aid procedures and financial support for college-related expenses.

As reported in Cunha et al. (2005), to assess the effectiveness of these programs, the performance of a group receiving intervention was compared with that of a control group. The comparisons were of performance over long periods of time, for example, under the Scope Perry Program the participants who were enrolled at the age 4 were observed until the age of 40 .

Cunha et al. (2005) concluded from the evidence of the above mentioned programs and from the Heckman et al. (1999) survey of evaluations of public job training programs that targeted young adults in the United States that the intervention in early ages is more effective than is intervention at later ages. Early intervention improves the performance of children in school in terms of less grade repetition, a higher probability of graduation and higher test scores. Furthermore and most importantly, crime rates for individuals who received interventionary help in their pre-school years are much lower than for those in the control group. In contrast, intervention in the adolescent years only alleviates and does not reverse early damage caused by low quality family environments. The participants show a higher average grade point, a higher rate of college attendance, a lower crime rate and higher test scores. However, the differences with the control groups are not large and the cost of intervention per student is high. Furthermore, participants do not show significantly higher income in later working years. Even when some higher income of the participants is found, it does not lift most of the treated people out of poverty. Thus, the intervention in late adolescent and young adult years is costly and not very effective.

Cunha et al. (2005) argue from the above evidence on interventions, that investments in human capital at different ages are direct complements. Assuming that this conclusion works not only with American, but works with human being in general, including Vietnamese; this conclusion would ring a bell on the too-rapid expansion of the tertiary education system in Vietnam as being discussed in section 5.2 below:

\subsection{Implication for Vietnam}

\subsubsection{Evidence of Insufficient Investment in Early Education in Vietnam}

Table 3. Educational expenditure in primary education as $\%$ of total educational expenditure

\begin{tabular}{llll}
\hline Countries & 2008 & 2009 & 2010 \\
\hline Australia & 35 & 36 & na \\
Cambodia & na & na & 42 \\
Indonesia & 49 & 48 & 44 \\
Philippines & 51 & 55 & na \\
Thailand & 45 & 46 & 40 \\
Vietnam & 29 & na & 34 \\
\hline
\end{tabular}

Source: World Bank (2013) 
Vietnam is well-known for her effort to implement universal education for low levels of education, especially for primary education. However, the investment for this level of education is relatively very low as indicated by the Table 3. More specifically, the share of educational expenditure in primary education as a percentage of total educational expenditure in Vietnam is lowest in the region. If we assume that highly developed countries, for example Australia, is closed to a market economy, in which investment in education is more or less optimally determined, than it can be seen from Table 3 that the investment in primary education in Vietnam is much lower than its (first-best) optimal level.

Table 4 gives further evidence of insufficient investment in early education in Vietnam. The student/teacher ratio for Vietnam is among the highest in East Asia, for pre-primary, primary as well as for secondary general education.

Table 4. Student/Teacher ratio by level of education

\begin{tabular}{lllllll}
\hline \multirow{2}{*}{ Economy } & \multicolumn{2}{l}{ Pre-primary } & Primary & \multicolumn{2}{c}{ Secondary General } \\
& 1985 & 1995 & 1985 & 1995 & 1985 & 1995 \\
\hline PRC & 27 & 31 & 25 & 24 & 18 & 16 \\
Hong Kong, China & 30 & 21 & 27 & 24 & 23 & 20 \\
Indonesia & 22 & 17 & 25 & 23 & 15 & 14 \\
Lao PDR & 16 & 16 & 25 & 30 & 12 & 13 \\
Malaysia & 32 & 23 & 24 & 20 & 22 & 19 \\
Singapore & 23 & - & 27 & - & 22 & - \\
Taipei, China & 19 & 15 & 32 & 22 & 21 & 18 \\
Thailand & 20 & & 19 & 20 & 18 & 20 \\
Viet Nam & 26 & 25 & 34 & 34 & 23 & 25 \\
\hline
\end{tabular}

ADB (2001)

\subsubsection{Evidence of Relatively High Investment in Tertiary Education in Vietnam and Policy Implication}

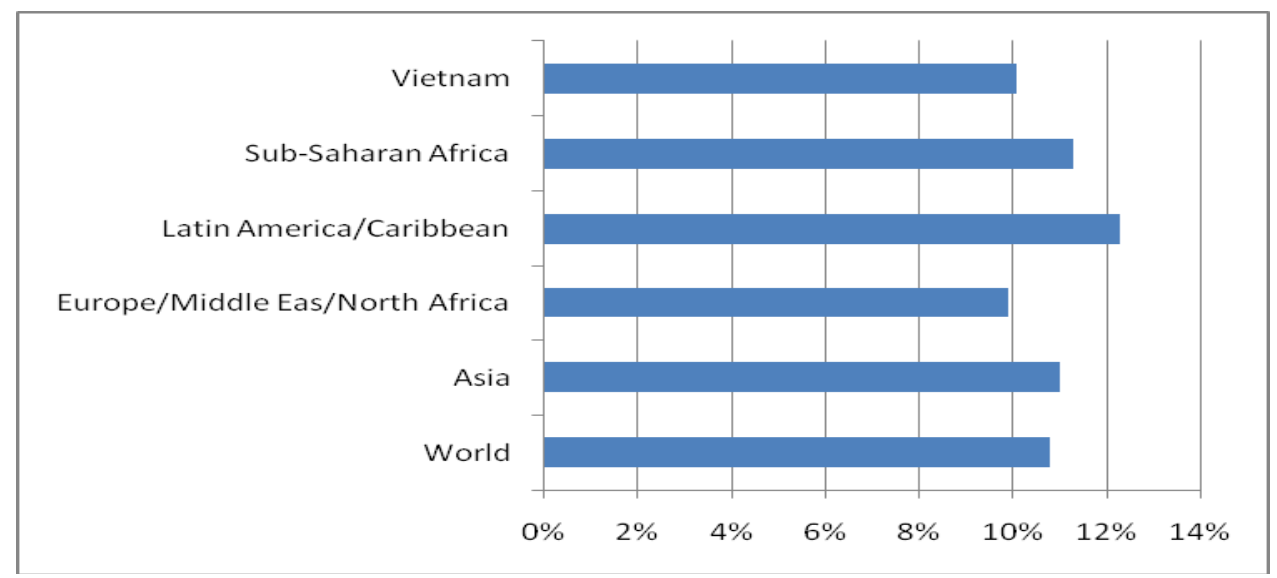

Figure 5. Returns to investment in tertiary education, latest year

Source: For Vietnam: Worldbank (2008); for others: Psacharopoulos G., \& Patrinos H. A. (2002)

Tertiary education system in Vietnam has been sharply expanding. There were 178 universities and colleges in 2000, but the number jumps to 277 in 2005 and again, to 414 in 2011. The number of students also jumps from 0.9 million in 2000 to 1.4 million in 2005 and 2.2 million in 2010 (GSO, 2012). Thus, within only 10 years, the scale of tertiary education has more than doubled, in terms of both the number of universities and colleges and the number of students. According to Vietnam (2011), the country plans to have up to 575 universities and colleges which will enroll up to 3.4-3.9 million students by the year 2020. Apart from rapid expansion in scale, the investment (per student) in tertiary education in Vietnam is also relatively high and this is implicitly indicated by Figure 5, which shows that returns to investment in tertiary education in Vietnam is lower than most of the 
regions in the world and lower than the average level of the world (remind that, the law of diminishing return indicates that the higher the level of investment, the lower the rate of return).

Another evidence of relatively high investment in tertiary education in Vietnam is reflected by its very high ratio to GDP as indicated in Table 5. Again, if we assume that highly developed countries, for example Japan or Singapore, are closed to a market economy, in which investment in education is closed to its optimal level, than it can be seen from Table 5 that the investment in tertiary education in Vietnam is much higher than than its (first-best) optimal level.

Table 5. Tertiary expenditure as those of GDP in selected country, latest Year

\begin{tabular}{llllll}
\hline No & Country & \% of GDP & No & Country & \% of GDP \\
\hline 1 & Japan & 0.61 & 6 & Indonesia & 1.2 \\
2 & Singapore & 1.07 & 7 & Philippines & 0.34 \\
3 & Hong Kong & 1.03 & 8 & Mongolia & 0.93 \\
4 & South Korea & 0.63 & 9 & Lao PDR & 0.21 \\
5 & Thai Land & 0.71 & 10 & Cambodia & 0.05 \\
& & 11 & Vietnam & 1.18 \\
\hline
\end{tabular}

Source: Jonathan D. London (2011)

\subsubsection{Policy Implication}

In Vietnam, to get a seat at a university or college, apart from financial capacity, students have traditionally taken a very serious entrance exam. Their scores are, then, ranked top-down and a cut-off score is chosen so that a pre-determined number of students will be selected. Thus, there is no doubt that selected students are better people, who have generally acquired good primary and secondary education. By expanding the tertiary education scale too fast as introduced above, the cut-off score has seriously been and will be further lowered to enroll much more, indicating that many students with poor primary and secondary education will be selected. Instead of joining the labor force or going to a vocational training center, those "bad" students go to universities and colleges with a much higher level of investment. This tendency may goes against the rule of negative remediation indicated by our model (Note 4), and thus, investment in education is not optimally made country-wide, leading to a waste in educational investment.

\section{Conclusion}

This paper examines aspects of the second-best optimal level of investment in late education, when investment in early education is not at its first-best optimal level. The analysis is done based on a vintage model of education, which is effectively an extension of the model of Cunha et al. (2005) by replacing an exogenously-determined target level of human capital with the optimization of a social welfare function.

The paper defines first-best optimal as the case when there are no exogenous constraints on investment in education in any period, so investment in education in each period is determined optimally; the second-best optimal as the case when the investment in early education is exogenously set and the investment in later education is optimally set, subject to the exogenous level of investment in early education. The paper emphasizes the case when the investment in early education is exogenously set below its optimal level given by the first-best, although the results can easily be interpreted for the case of excessive investment in early education.

The paper also defines full remediation is the case when the deficiency in investment in early education is fully offset by an increase in investment in later education such that there is no deficiency in human capital. Outcomes where the second-best optimal level of human capital is less than its first-best level can be categorized into three cases. Partial remediation is the case when the deficiency in investment in early education is partially offset by an increase in investment in later education above its first-best level. No remediation is the case when the deficiency in investment in early education is not offset by an increase in investment in later education above its first-best level. Finally negative remediation is the case when the deficiency in investment in early education is accompanied by a decrease in investment in later education to below its first-best level.

This paper applies a definition of complementarity, which is presented Hoan Pham Xuan (2009) and Cunha et al. (2005) that if a higher level of investment in education in one period results in a higher productivity of the investment in education another period, then the investments in two periods are direct complements. 
Furthermore, if a higher level of investment in education in one period does not affect the productivity of the investment in education in another period, the investments in education in two periods are defined as independent. And if a higher level of investment in education in one period will result in a lower productivity of the investment in education in another period, then the investments in two periods are defined as direct substitutes. When they are direct substitutes and one unit of investment in one period of education can perfectly substitute for another unit of investment in another period of education, they are perfect substitutes.

This paper shows that, if education investments are direct complements, then negative remediation of human capital is optimal, that is, the second-best level of investment in later education and of human capital are lower than their first-best optimal levels. If educational investments are independent, no remediation of human capital is optimal, that is the second-best level of investment in later education is equal to its first-best optimal level. No human capital deficiency in human capital formation in early education is offset or added to by the investment in investment in later education. If education investments are direct (but not perfect) substitutes, partial remediation of human capital is optimal, that is the second-best optimal level of investment in later education is higher than its first-best optimal level so that human capital deficiency in human capital formation in early education is partly offset by the investment in human capital formation in later education. If education investments are perfect substitutes, full remediation of human capital is optimal, that is the second-best optimal level of investment in late education is higher than its first-best optimal level so that human capital deficiency in human capital formation in early education is fully offset by the investment in human capital formation in later education.

The finding of this paper that negative remediation in human capital is socially optimal when investments in different years of education are complements adds to the case put by Cunha et al. (2005) that low levels of human capital at early years should be viewed with considerable concern. The paper has shown that low investment in early years would induce social planners to cut back on investment in later years. Education planners, for example, would find from cost-benefit analysis that less rather than more investment was second-best optimal. Early deficiencies would be reinforced by the planning process. Parents would face similar incentives.

Observing the effectiveness of various remediation programs, which target pre-school, primary, secondary and college students in the United States, Cunha et al. (2005) state that investments in education are direct complement. Given the fact that investment in early education in Vietnam is insufficient, the statement of Cunha et al. (2005) would signal that the too-rapid expansion of the tertiary education system in Vietnam is not economically optimal. This is because that, by providing university education for low quality entrance-students, the country is making positive remediation rather than negative remediation as suggested by our model, thus reducing the efficiency of educational investment.

This research can be extended in two directions. First, the assumption of exogenous number of periods of education can be relaxed to study (i) if the conclusion about the second-best optimal level of human capital in this paper be affected and (ii) if the second-best number of periods of education is less than, equal or greater than its first-best optimal number. This issue will be settled in the next research of the authors. Second, we can look at the case of a disaggregated model, in which only a subset of a cohort suffers from below the first-best optimal level of investment in early education. In such a framework, the effect on remediation of distributional weights on individuals' welfare could be calculated. How great do these weights have to be for partial rather than negative remediation to be second-best optimal? And what do actual decisions about investment remediation imply for the values of the weights implicitly chosen by society? Many regards education as a "right" and so would argue that public policy should offset any deficiencies, such that people who suffered from low level of education in early education are not permanently disadvantaged, in term of lower level of human capital during their adult lives. What social welfare function could underlie the views of those who regard full remediation as a right? These are difficult issues that require public debate to be settled. (Note 5)

\section{References}

Asia Development Bank. (2001). Education \& National Development in Asia: Trend, Issues, Politics and Strategy.

Bils, M., \& Klenow, P. (2005). Does Schooling Cause Growth. The American Economics Review, 90(5).

Cutler, D. M., Poterba, J. M., Sheiner, L. M., \& Summers, L. H. (1990). An Ageing Society: Opportunity or Challenge? Brookings Papers on Economic Activities, 1. http://dx.doi.org/10.2307/2534525

Flavio, C., James, J. H., Lance, L., \& Dimitriy, V. M. (2005). Interpreting the Evidence on Life Cycle Skill Formation. Discussion Paper No. 1675, Institute for the Study of Labor. 
Gregory, N. M., David, R., \& David, N. W. (1992). A Contribution to the Empirics of Economic Growth. Quarterly Journal of Economics, 107.

GSO (General Statistic Office of Vietnam Government). (2002). Retrieved from http://www.gso.gov.vn

Guest, R. S., \& McDonald, I. M. (1998). The Socially Optimal Level of Saving in Australia, 1960-61 to 1994-95. Australian Economic Papers, 37(3). http://dx.doi.org/10.1111/1467-8454.00017

Guest, R. S., \& McDonald, I. M. (2001). The Volatility of the Socially Optimal Level of Saving. Journal of Policy Modeling, 23(8). http://dx.doi.org/10.1016/S0161-8938(01)00093-X

Hoan, P. X. (2007). The Socially Optimal Level of Education and Human Capital. Phd Thesis, Melbourne University.

Hoan, P. X. (2009). Optimal Investment, Education and Consumption under Demographic Changes for a Small-Open Economy. Singapore Economic Review, 54(1).

Imhoff, E. V. (1988). Optimal Investment in Human Capital under Conditions of Nonstable Population. Journal of Human Resources, 14, 3.

Imhoff, E. V., \& Ritzen, J. (1988). Age Structure, Education and the Transmission of Technical Change. Journal of Population Economics, 1(3).

James, J. H. (2004). Productivity Argument for Investing in Young Children. Working Paper 5, Invest in Kids Working Group Committee for Economic Development.

James, J. H., LaLonde, R. J. R., \& Smith, J. (1999). The Economics and Econometrics of Active Labour Market Programs. In O. Ashenfelter, \& D. Card (Eds.), Handbook of Labour Economics (Vol. 3). Amsterdam: Elsevier.

Jonathan, D. L. (2011). Education in Vietnam, Institute of Southeast Asia Studies, Singapore (Figure 11.2), 306.

Paul, G., \& Hanan, J. (2004). Economic Growth and the Demand for Education: Is there a Wealth Effect? Journal of Development Economics, 74, 1.

Phuong, N. M. (2012). Strengthen the Socialization Process in the Areas of Education, Healthcare in Vietnam. The National Political Publisher, Vietnam.

Psacharopoulos, G., \& Patrinos, H. A. (2002). Returns to Investment in Education: A Further Update. World Bank Policy Research, Working Paper, No. 2881, Washington DC.

Robert, M. S. (1956). A Contribution to the Theory of Economic Growth Quarterly Journal of Economics, 19.

Schultz, T. W. (1960). Capital Formation by Education. Journal of Political Economy. http://dx.doi.org/10.1086/ 258393

Vietnam. (2011). Decision Number 1216/QD-TTg dated 22/7/2011 on the Approval of the Human Capital Development Master Plan for Period 2010-2020.

Worldbank. (2008). Vietnam: Higher Education and Skills for Growth, Report of the Human Development Department, East Asia and Pacific Resion.

Worldbank. (2012). Putting Higher Education to Work: Skills and Research for Growth in East Asia, World Bank East Asia and Pacific Regional Report.

Worldbank. (2013). World Development Indicator.

\section{Notes}

Note 1. See appendix 1 for this detailed discussion.

Note 2. In this paper, very often, very often, one period cans be seen as one year.

Note 3. "Early education" is a short writing for "education in early years". "Later education" is a short writing for "education in later years".

Note 4. Recal that in this paper, primary and secondary education is seen as early education; university education is seen as late education.

Note 5. Because the focus of analysis in this paper is on how to deal with low levels of investment in early education, no mechanism is included to explain why investment would be at such low levels. However, the 
model developed in this paper would be the natural starting point to incorporate such a mechanism, that is left for further work.

\section{Appendix A}

Complementarity and substitution.

The following explanation about complementarity and substitution is quoted from Cunha et al. (2005):

"Complementarity has multiple definitions in economics and these definitions are not equivalent (Samuelson, (1974). The two polar cases, perfect substitutes and perfect complements, have been a part of the economist's toolkit at least since Fisher (1892). A production function for output, $g(x, y)$, defined in term of input $(x, y)$, is said to exhibit perfect substitution among the inputs if the output $g(x, y)$ is:

$$
g(x, y)=g(a x+(1-a) y), 0<a<1
$$

Thus $x$ and $y$ substitute perfectly in the sense that one unit of $y$ produces exactly the same output as $(1-a) / a$ units of $x$ for all levels of $x$ and $y$. If $x$ is an early input and $y$ is a late input, technically one can always remediate for a low $x$ by a compensation in term of $y$. If $a=1$, this is not possible. The closer $a$ is to 1 , the greater the required remediation in term of $y$.

Perfect complementarity characterizes $g(x, y)$ if $g(x, y)=g(\min (x, y))$

This is an "O ring" technology where output is limited by the weakest link (the lowest level of input). Thus if $x$ is an early input, a low level of $x$ cannot be remediated by any investment in $y$. Another implication of this technology is that if $x$ is big, a low level of $y$ undoes the early investment.

A second definition of complementarity and substitution, sometimes called direct substitution or complementarity, for a twice differentiable $g(x, y)$ is that

Input $(x, y)$ are direct complements if $\partial^{2} g(x, y) / \partial x \partial y>0$

while $(x, y)$ are direct substitutes if $\partial^{2} g(x, y) / \partial x \partial y<0$

Input $(x, y)$ are independent if $\partial^{2} g(x, y) / \partial x \partial y=0$.

What is confusing is that the two definitions do not always agree. Suppose that $g(x, y)=a x+(1-a) y$. Then $(x, y)$ are perfect substitutes under the first definition, but are independent inputs under the second definition. Note further that if $(x, y)$ are perfect complements under the first definition $g$ is not everywhere differentiable.

However, if $g$ is strictly concave and differentiable, $(x, y)$ are perfect substitutes under either definition. To make matters worse if $g(x, y)$ is homogeneous of degree one and $\partial^{2} g(x, y) / \partial x^{2}<0$, then it is a consequence of Euler's Theorem that $\partial^{2} g(x, y) / \partial x \partial y>0$ so that inputs are direct complements". 


\section{Appendix B}

1. Showing that $\partial I_{2}^{2 n d b e s t} / \partial \bar{I}_{1}>0$ for the case of complementarity:

Suppose that the investment in early education was optimally made, instead of being exogenously made at $\bar{I}_{1}$, then the first order conditions for $I_{1}$ and $I_{2}$ from (9) imply that investment in year 1 education is equal to the investment in education in year 2, so the first-best optimal investment in each year can be derived from (10) as:

$$
I_{1}^{1 s t b e s t}=I_{2}^{1 s t b e s t}=Z^{\phi} 2^{\phi p}
$$

Around the first-best optimal, the investments in education in years 1 and 2 are equal to each other so equation (11) becomes:

$$
\partial I_{2}^{\text {around lstbest }} / \partial \bar{I}_{1}=-(\phi+v-1) /(\phi+v-1)+2(1-v)\left(I_{1}^{1 \text { stbest }}\right)^{v}
$$

Substituting the first-best optimal investment in education in year 1 in (14), recalling the value of $Z$ is given by (1), equation (15) becomes:

$$
\partial I_{2}^{\text {around 1 stbest }} / \overline{\partial I_{1}}=(1-\phi-v) /(1-\phi-v)+2^{\frac{(1-v)}{\phi}}(1-v)\left[(1-\phi)(p-2) \sigma^{\frac{\alpha}{1-\partial} l^{\phi}}\left(\alpha^{\frac{\alpha}{1-\alpha}}-\alpha^{\frac{1}{1-\alpha}}\right)\right]^{\frac{v}{\phi}}
$$

Under the case of complementarity, $(\phi+v<1)$. Apart from this, $(1>v, \phi, \alpha, \beta>0)$ under our assumptions and $(p>2)$ because normally a person will work for many years after finishing school education on. Therefore, both the numerator and denominator of (16) is positive. Thus, it follows from (16) that:

$$
\partial I_{2}^{\text {around } 1 \text { stbest }} / \partial \bar{I}_{1}>0
$$

2. Showing that $\partial I_{2}^{2 n d b e s t} / \partial \bar{I}_{1}<0$ for the case of direct substitution (but not perfect substitution):

Direct substitution is represented by $(\phi+v>1)$. The inequality $\partial I_{2}^{\text {around } 1 \text { stbest }} / \partial \bar{I}_{1}<0$ can be easily proved, by doing similarly to the section 1 .

\section{Copyrights}

Copyright for this article is retained by the author(s), with first publication rights granted to the journal.

This is an open-access article distributed under the terms and conditions of the Creative Commons Attribution license (http://creativecommons.org/licenses/by/3.0/). 